\title{
RESEARCH
}

Open Access

\section{The Trp64Arg polymorphism in $\beta 3$ adrenergic receptor (ADRB3) gene is associated with adipokines and plasma lipids: a systematic review, meta-analysis, and meta-regression}

Zhi Luo ${ }^{1 *+}$, Ting Zhang ${ }^{2 \dagger}$, Shengping Wang ${ }^{3}$, Yuxian $\mathrm{He}^{3}$, Qiutang Ye $\mathrm{e}^{4}$ and Wenzhai Cao ${ }^{{ }^{*}}$

\begin{abstract}
Background: Recently, some studies claim that adipokines may modulate plasma lipids. More interestingly, the ADRB3 Trp64Arg polymorphism may regulate adipokines and play an essential role in lipids metabolism. This study aims to clarify the associations of ADRB3 Trp64Arg polymorphism with plasma adipokines and lipid levels.

Methods: Twenty-two studies (5527 subjects) and 121 studies (54,059 subjects) were respectively identified for the association analyses of adipokines and lipids. Standardized mean difference (SMD) and 95\% confidence interval (CI) were used to estimate the strength of the Trp64Arg variant in adipokines and plasma lipids. All results were recalculated after eliminating the studies with heterogeneity.

Results: The carriers of the $C$ allele (Arg at 64th position was encoded by the $C$ allele) had higher levels of leptin and lower levels of adiponectin than the non-carriers. The carriers of the $C$ allele had higher levels of triglycerides (TG), total cholesterol (TC), and lower levels of high-density lipoprotein cholesterol (HDL-C) than the non-carriers. Subgroup analysis certified an ethnicity (Asians), disease status (obesity), and gender (females) specific association. Sensitivity analysis indicated that the analysis results were robust and stable. Meta-regression indicated that obesity was related to adiponectin.
\end{abstract}

Conclusions: The $\mathrm{C}$ allele carriers of Trp64Arg polymorphism had a slight but significant influence on lipid levels, and the remarkable effects specific existed in obese Asian women. The associations of Trp64Arg polymorphism with dyslipidemia may partly be mediated by the effect of this polymorphism on adipokines. The association of Trp64Arg polymorphism with obesity may partly be mediated by the effect of this polymorphism on adipokines. The $C$ allele carriers had abnormal levels of adipokines and lipids, and it indicated that the Trp64Arg polymorphism might represent a genetic risk factor for coronary artery disease (CAD).

Keywords: ADRB3, Trp64Arg, Polymorphism, Adipokines, Plasma lipids, CAD, Obesity

\footnotetext{
* Correspondence: drzhiluo@foxmail.com; caowenzhai@163.com

'Zhi Luo and Ting Zhang contributed equally to this work and should be considered as co-first authors.

'Department of Cardiology, The First People's Hospital of Zigong, Zigong 643000, People's Republic of China

Full list of author information is available at the end of the article
}

(c) The Author(s). 2020 Open Access This article is licensed under a Creative Commons Attribution 4.0 International License, which permits use, sharing, adaptation, distribution and reproduction in any medium or format, as long as you give appropriate credit to the original author(s) and the source, provide a link to the Creative Commons licence, and indicate if changes were made. The images or other third party material in this article are included in the article's Creative Commons licence, unless indicated otherwise in a credit line to the material. If material is not included in the article's Creative Commons licence and your intended use is not permitted by statutory regulation or exceeds the permitted use, you will need to obtain permission directly from the copyright holder. To view a copy of this licence, visit http://creativecommons.org/licenses/by/4.0/ The Creative Commons Public Domain Dedication waiver (http://creativecommons.org/publicdomain/zero/1.0/) applies to the data made available in this article, unless otherwise stated in a credit line to the data. 


\section{Introduction}

CAD obtains the highest mortality and disability rate in most of the developed and developing countries. CAD is triggered by multiple genetic and environmental risk factors. Among these risk factors, the abnormal levels of adipokines [1, 2] and lipids [3] are widely reported about their essential roles in the occurrence and progress of CAD. Both leptin and adiponectin are called adipokines, produced by white adipose tissue, one of the most potent lipid regulator [4-6], and plays a vital role in lipid metabolism [7-9]. Some new shreds of evidence have shown that leptin is positively related to dyslipidemia [10-12] in contrast to adiponectin, which is negatively related to dyslipidemia [13-15]. Considering the leptin is considerably increased, and the adiponectin is substantially decreased in obese mice [16]. Leptin promotes, and adiponectin prevents atherosclerosis [17] by aiming directly on blood vessel endothelial cells. The adipokines are becoming an indispensable bridge between obesity, dyslipidemia, and atherosclerosis [18-20]. As the leptin/adiponectin ratio serves as a new atherosclerotic indicator [21], it is a sensitive index in estimating obesity and dyslipidemia.

The beta-adrenergic receptors (ADRBs) are composed of the $\beta 1$ adrenergic receptor (ADRB1), $\beta 2$ adrenergic receptor (ADRB2), and ADRB3. The ADRB1 and ADRB2 located in myocytes and play an essential role in its function regulation $[22,23]$. By contrast, the ADRB3 subtype located in white adipose tissue and plays a critical role in regulating lipolysis in white adipose tissue [24, 25]. The ADRB3 gene is located on the long arm of human chromosome 8 (8p11.1-12), and it contains two exons and one intron. The Trp64Arg polymorphism (also known as T190C, W64R, and rs4994) is the only function mutation of the $A D R B 3$ gene, located in exon one and caused by substitution from thymine (T) to cytosine (C). Previous studies have reported that the $A D R B 3$ gene might regulate the expression levels of adipokines [26, 27] and plasma lipids [28, 29]. Also, the Trp64Arg polymorphism was proved to be related to obesity [30-32] and relevant characteristics [33, 34] in Pima Indians and western obese patients. Whereas the $A D R B 3$ gene might influence the plasma levels of adipokines and lipids and the Trp64Arg polymorphism might be associated with obesity-related traits, it is not difficult to speculate that the Trp64Arg variant might influence the plasma levels of adipokines and lipids. Recently, Chen et al. [35] have reported that the Trp64Arg variant is closely related to CAD. However, the specific mechanisms are not precise, so there is an urgent need to clarify the associations of Trp64Arg polymorphism with plasma adipokines and lipid levels, to provide some clues or references for the clarification of possible mechanisms of Trp64Arg polymorphism with CAD.

It is worth noting that this is the first systematic review, meta-analysis, and meta-regression to assess the associations of the Trp64Arg polymorphism with adipokines and plasma lipids in a large sample size (59,586 subjects of 122 studies). Besides, the present systematic review may generate some new information. Some studies have reported that the Trp64Arg variant was positively associated with adipokines and plasma lipids. On the contrary, other studies have indicated that the Trp64Arg variant was negatively associated with adipokines and plasma lipids. However, the results from a few studies did not support these associations. Since the present study results are controversial and inconclusive, a systematic review, metaanalysis, and meta-regression are required to unveil whether this polymorphism affects adipokines and plasma lipids or not. Moreover, if it does, so whether it is positive or negative in the light of evidence-based medicine.

\section{Methods}

Literature search

A comprehensive literature review was performed before Jan 2020 by using nine databases including PubMed, Cochrane Library, Medline, Embase, Web of Science, Google Scholar, Wanfang, China National Knowledge Infrastructure (CNKI), and China Biology Medicine (CBM) database by using Keywords: “ADRB3" or "beta3-adrenergic receptor" or " $\beta 3$-adrenergic receptor" or “B3AR"), ("Trp64Arg" or “T190C" or "rs4994"), ("polymorphism" or "mutation" or "variant"), ("adipokines"), ("adiponectin"), ("leptin") and ("circulating lipid" or "blood lipid" or "plasma lipid" or "serum lipid").

\section{Inclusion criteria}

The inclusion criteria for this systematic review are as below: (1) The studies have examined the associations of Trp64Arg polymorphism with adipokines and plasma lipids. (2) The studies have at least offered one of the variables in adipokines profile (leptin and adiponectin) or lipids profile [TG, TC, low-density lipoprotein cholesterol (LDL-C), and HDL-C]. (3) The studies have offered the mean adipokines or lipids with standard deviation (SD) by genotypes. (4) The studies have provided the allele or genotype frequencies of the Trp64Arg polymorphism. (5) The language of included studies is restricted to English and Chinese. The exclusion criteria for this study are as below: (1) Studies not related to Trp64Arg polymorphism; (2) studies do not offer genotype or allele frequencies; (3) studies present invalid data; (4) pedigree studies; (5) overlapping studies; (6) abstract, review, systematic review, meta-analysis, and animal studies.

\section{Data extraction}

According to a pre-piloted data extraction form and the pre-specified selection criteria, two researchers independently extracted the data from each eligible study. Results were compared, and divergences about data extraction were settled by consensus. If crucial data were 
absent from included studies, e-mail, or telephone would be used to acquire these data. From each eligible study, the following data were extracted: the first author's name, the publication year, language, country, ethnicity, disease status, gender, genotype counts, total sample size, and mean plasma levels of adiponectin, leptin, and lipids with SD by genotypes.

\section{Data analysis}

All the tests were performed by STATA software (version 15.0, College Station, TX). $P$-values less than 0.05 were considered to be statistically significant. The Chi-square test estimated the Hardy-Weinberg equilibrium (HWE) among control subjects. Publication bias was tested by Begg's funnel plot and Egger's test [36]. SMD with 95\% CIs were used to assess the effects of the Trp64Arg variant on plasma adipokines and lipid levels. Sensitivity analysis was used to check the robustness and stableness of all results. The random-effect model was performed to analyze the results if heterogeneity among the involved studies was remarkable. Otherwise, the Fixed-effect model would be used [37]. Galbraith plots and meta-regression analysis estimated the sources of heterogeneity among studies. All SMD with 95\% CIs were recalculated after excluding the study with heterogeneities. The confounding factors included publication year (before 2000 and after 2000)), language (English and Chinese), ethnicity (Caucasian, Asian, Chilean, Brazilian, Indonesian and Other ethnic), gender
(Males or Females), disease status [Obesity, CAD, type 2 diabetes mellitus (T2DM), and Hypertension] and total sample size $(\geq 500$ subjects and $<500$ subjects). Subgroup analyses were conducted by ethnicity, disease status, gender, healthy subjects, and children subjects. The ethnic subgroup was divided into Caucasian, Asian, Chilean, Brazilian, Indonesian, and other ethnicities. Disease status was divided into Obesity, CAD, T2DM, and Hypertension.

\section{Result}

\section{Characteristics of the included studies}

The initial search of the databases yielded 2568 studies. Two thousand two hundred and ninety-seven studies were excluded by its contents. Then 167 studies were reevaluated by the inclusion criteria. Forty-five studies were further excluded due to the following reasons: twenty-five studies offered data of other polymorphisms, ten studies offered invalid data, five studies had subjects overlapping with other publications, and five studies were based on pedigree analysis. Finally, 122 studies were included for this systematic review (Fig. 1). Of them, 22 studies (5527 subjects) and 121 studies (54,059 subjects) were identified for the association analyses of adipokines and lipids, respectively.

The references of the included studies were listed in Additional file 1. The characteristics of the included studies were presented in Additional file 1: Table S1. The plasma adipokines and lipid levels by the genotypes of the ADRB3 Trp64Arg polymorphism were presented in

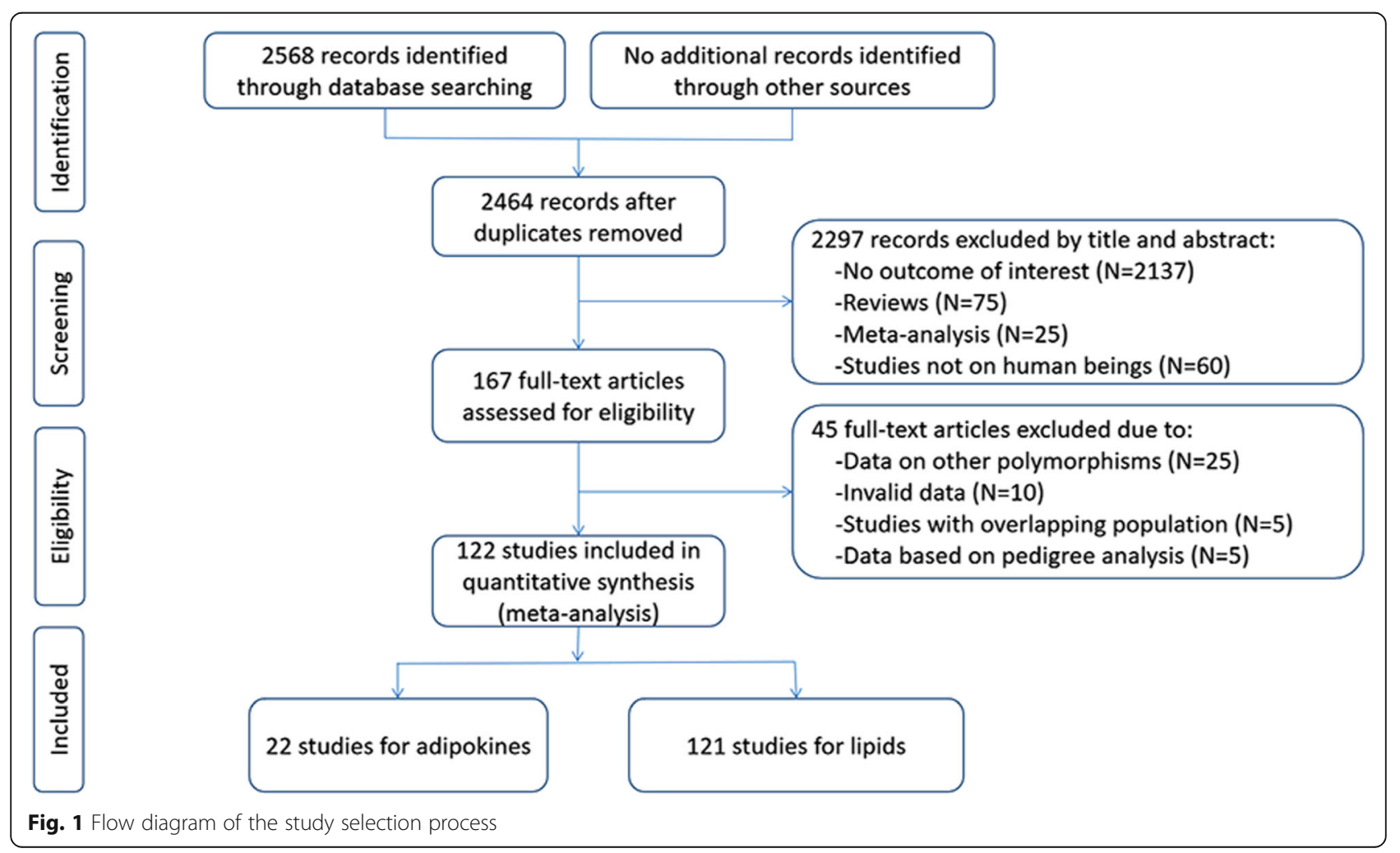


Additional file 1: Table S2 and Additional file 1: Table S3, respectively. The sources of heterogeneity of TG, HDL-C, adiponectin, leptin, TC and LDL-C were respectively presented in Additional file 1: Table S4, Additional file 1: Table S5, Additional file 1: Table S6, Additional file 1: Table S7, Additional file 1: Table S8 and Additional file 1: Table S9.

\section{Association of the ADRB3 Trp64Arg polymorphism with plasma adipokines levels}

The $\mathrm{C}$ allele carriers had higher levels of leptin (Fig. 2) and lower levels of adiponectin (Fig. 3) than the noncarriers. When the analysis was confined to the studies in HWE (Table 1), the significant association of the Trp64Arg polymorphism with higher levels of leptin and lower levels of adiponectin were also detected.

Then the subgroup analyses were conducted (Table 1), and the analyses revealed that the Trp64Arg variant was related to higher levels of leptin in Asians, Males, and healthy subjects and lower levels of adiponectin in Asians.

The analyses eliminating the studies with heterogeneity were also conducted (Table 2), and the analyses showed that the Trp64Arg variant was related to higher levels of leptin in Caucasians, Asians, Males, and healthy subjects and lower levels of adiponectin in Caucasians and Asians.

\section{Association of the ADRB3 Trp64Arg polymorphism with plasma lipid levels}

The $C$ allele carriers had higher levels of TG and TC and lower levels of HDL-C than the non-carriers (Table 3). When the analysis was confined to the studies in HWE (Table 3), the significant association of the Trp64Arg polymorphism with higher levels of TG, TC, and lower levels of HDL-C were also detected.

Then the subgroup analysis by the characteristics of the subjects was performed (Table 3). Subgroup analysis by ethnicity showed that the significant associations of the Trp64Arg polymorphism with higher levels of TG, TC, and lower levels of HDL-C were detected in Caucasians and Asians, but not in the other ethnicities. Subgroup analysis by gender showed that the significant associations of the Trp64Arg polymorphism with higher levels of TG, $\mathrm{TC}$, and lower levels of HDL-C were only detected in the females, but not in the males. Subgroup analysis by disease status showed that the significant associations of the Trp64Arg polymorphism with higher levels of TG and TC

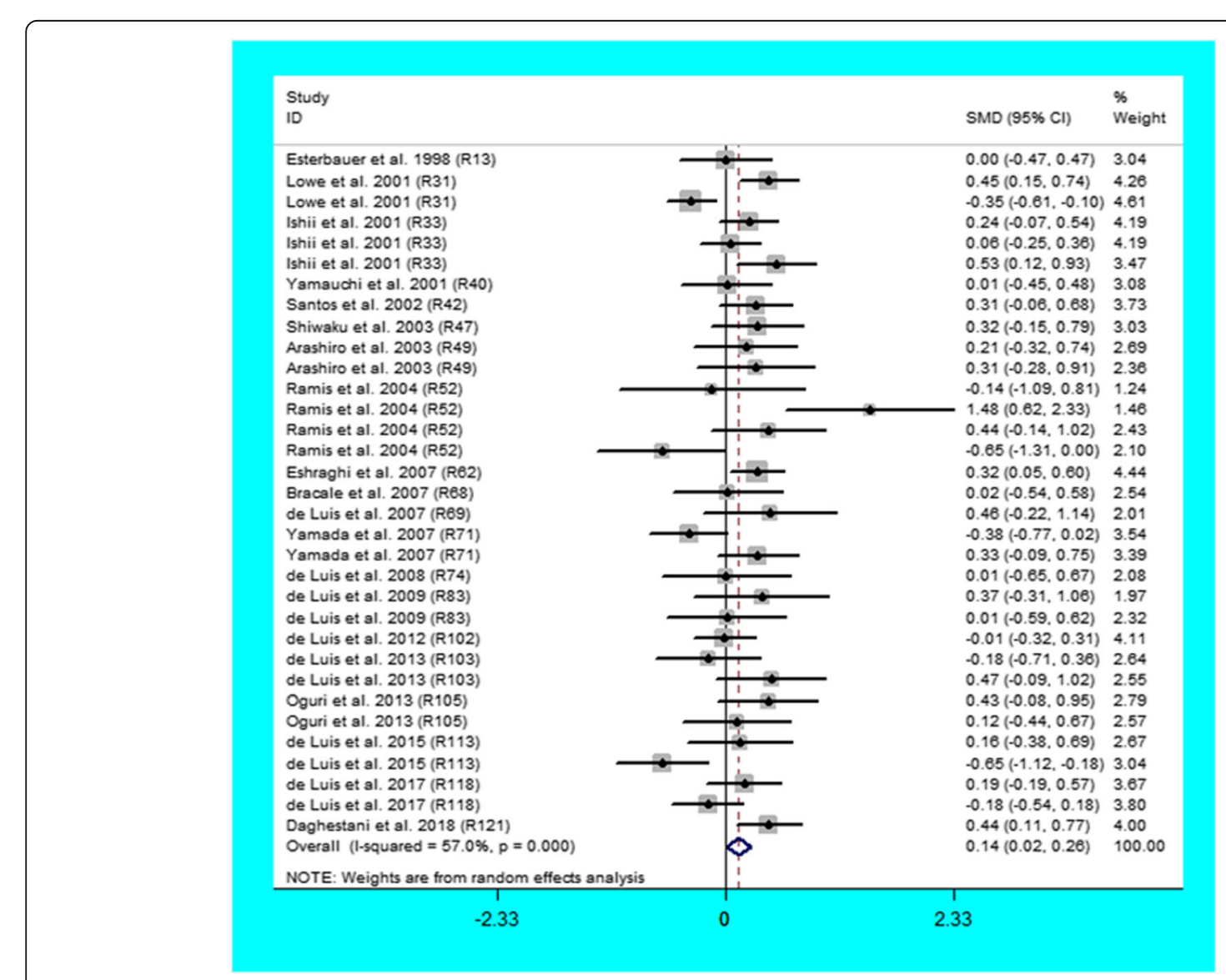

Fig. 2 Forest plot of the meta-analysis between the ADRB3 Trp64Arg polymorphism and leptin 


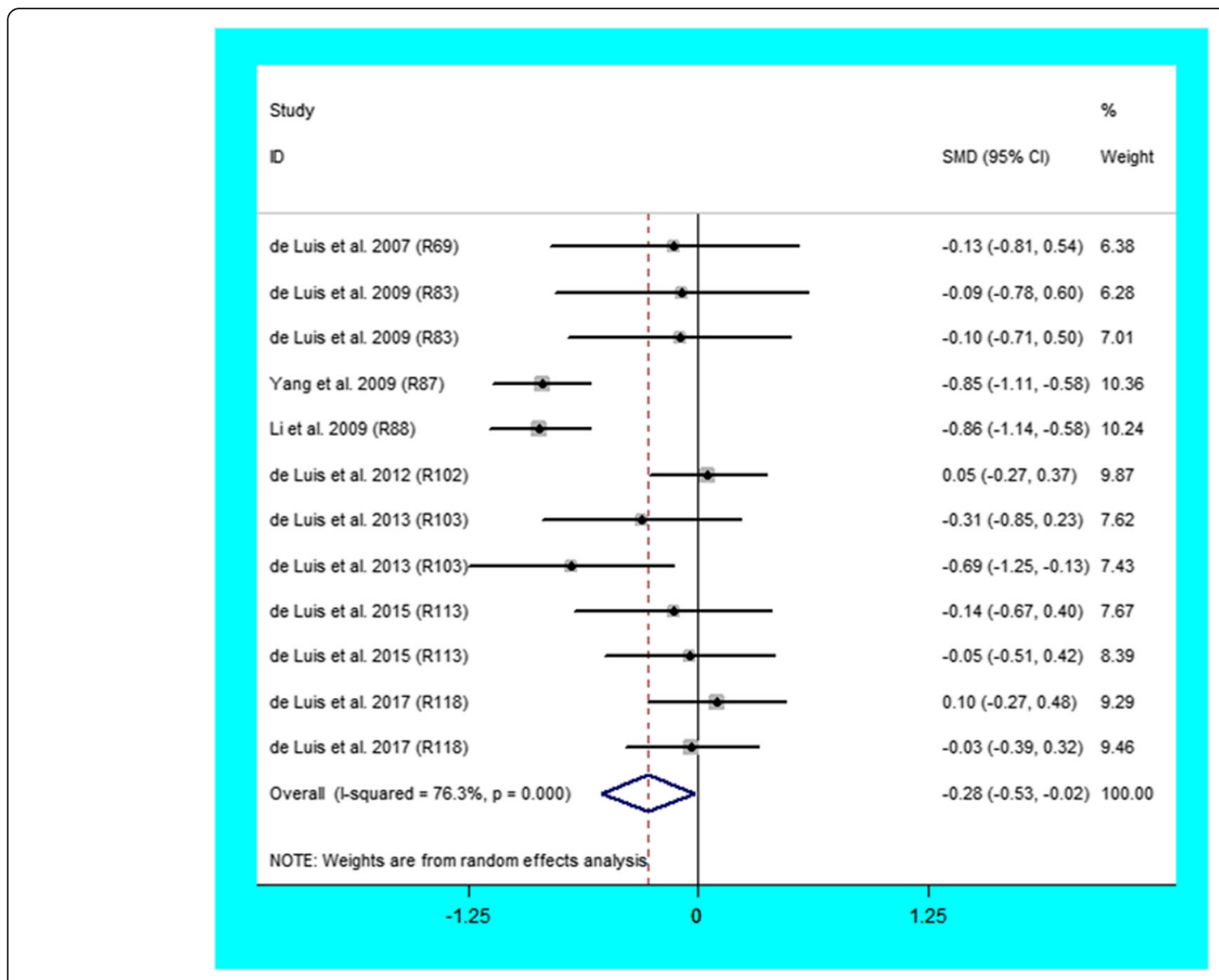

Fig. 3 Forest plot of the meta-analysis between the ADRB3 Trp64Arg polymorphism and adiponectin

Table 1 Meta-analysis of the ADRB3 Trp64Arg polymorphism with adipokines levels

\begin{tabular}{|c|c|c|c|c|}
\hline Groups or subgroups & Comparisons (Subjects) & SMD (95\% Cl) & $P_{\text {Heterogeneity }}$ & $P_{\text {SMD }}$ \\
\hline \multicolumn{5}{|l|}{ Leptin } \\
\hline All & 33 (4999) & $0.14(0.02-0.26)$ & $<0.001$ & 0.02 \\
\hline Studies in HWE & 31 (4594) & $0.12(0.00-0.24)$ & $<0.001$ & 0.05 \\
\hline Caucasian & 19 (3036) & $0.11(-0.06-0.28)$ & $<0.01$ & 0.21 \\
\hline Asian & $11(1124)$ & $0.18(0.03-0.33)$ & 0.18 & 0.02 \\
\hline Female & 9 (1416) & $0.11(-0.18-0.41)$ & $<0.001$ & 0.46 \\
\hline Male & $9(1161)$ & $0.22(0.02-0.42)$ & 0.04 & 0.03 \\
\hline Obesity & 19 (2418) & $0.08(-0.09-0.24)$ & 0.01 & 0.36 \\
\hline Healthy subjects & $12(2384)$ & $0.19(0.00-0.38)$ & $<0.001$ & 0.05 \\
\hline \multicolumn{5}{|l|}{ Adiponectin } \\
\hline All & $12(2073)$ & $-0.28(-0.53--0.02)$ & $<0.001$ & 0.03 \\
\hline Studies in HWE & $11(1800)$ & $-0.26(-0.39--0.13)$ & $<0.001$ & $<0.001$ \\
\hline Caucasian & $10(1545)$ & $-0.08(-0.23-0.07)$ & 0.64 & 0.28 \\
\hline Asian & $2(528)$ & $-0.86(-1.05--0.66)$ & 0.95 & $<0.001$ \\
\hline Obesity & $10(1545)$ & $-0.08(-0.23-0.07)$ & 0.64 & 0.28 \\
\hline
\end{tabular}


Table 2 Meta-analysis of the ADRB3 Trp64Arg polymorphism with adipokines levels after excluding the study with heterogeneity

\begin{tabular}{|c|c|c|c|c|}
\hline Groups or subgroups & Comparisons (Subjects) & SMD (95\% Cl) & $P_{\text {Heterogeneity }}$ & $P_{S M D}$ \\
\hline \multicolumn{5}{|l|}{ Leptin } \\
\hline All & $29(4581)$ & $0.17(0.09-0.24)$ & 0.08 & $<0.001$ \\
\hline Studies in HWE & $27(4176)$ & $0.14(0.06-0.23)$ & 0.07 & $<0.001$ \\
\hline Caucasian & $16(2733)$ & $0.16(0.05-0.27)$ & 0.46 & 0.01 \\
\hline Asian & $10(1009)$ & $0.24(0.11-0.37)$ & 0.80 & $<0.001$ \\
\hline Female & $7(1253)$ & $-0.02(-0.17-0.12)$ & 0.05 & 0.76 \\
\hline Male & $8(1046)$ & $0.30(0.16-0.44)$ & 0.52 & $<0.001$ \\
\hline Obesity & $16(2113)$ & $0.10(-0.02-0.22)$ & 0.83 & 0.11 \\
\hline Healthy subjects & $11(2271)$ & $0.19(0.09-0.30)$ & 0.06 & $<0.001$ \\
\hline \multicolumn{5}{|l|}{ Adiponectin } \\
\hline All & $8(1190)$ & $-0.63(-0.78--0.48)$ & 0.07 & $<0.001$ \\
\hline Studies in HWE & $7(917)$ & $-0.52(-0.70--0.34)$ & 0.10 & $<0.001$ \\
\hline Caucasian & $6(662)$ & $-0.26(-0.50--0.02)$ & 0.68 & 0.03 \\
\hline Asian & $2(528)$ & $-0.86(-1.05--0.66)$ & 0.95 & $<0.001$ \\
\hline Obesity & $6(662)$ & $-0.08(-0.23-0.07)$ & 0.64 & 0.28 \\
\hline
\end{tabular}

ADRB3 beta3-adrenergic receptor gene, SMD standardized mean difference, $95 \% \mathrm{Cl}$ 95\% confidence interval, HWE Hardy-Weinberg equilibrium

were only detected in obese patients, but not in CAD patients, T2DM patients, and hypertension patients. Besides, the significant association of the Trp64Arg polymorphism with lower levels of HDL-C was detected in obese patients and T2DM patients, but not in CAD patients and hypertension patients. When the analysis was limited to healthy subjects, the significant association of the Trp64Arg polymorphism with higher levels of TG and TC were also detected.

The analyses eliminating the studies with heterogeneity were also conducted (Table 4), and the analyses revealed that the Trp64Arg variant was related to higher levels of TG, TC, and lower levels of HDL-C in Asians, females and obesity patients after excluding the outlier studies. However, the association analysis of the Trp64Arg variant with lipid levels did not show statistically significant in Caucasians and healthy subjects. Besides, the significant association of the Trp64Arg variant with higher levels of LDL-C was detected in Asians. This indicated that the significant associations of the Trp64Arg variant with plasma lipid levels in obese Asian women were stable and robust.

\section{Evaluation of heterogeneity}

In the association analysis of adipokines, significant heterogeneity was identified in the total comparisons of leptin and adiponectin (Table 1). Four and four comparisons were recognized as the main contributors to the heterogeneity for leptin and adiponectin, respectively, by performing Galbraith plots. The analysis results of leptin and adiponectin did not change substantially after excluding the outlier comparisons (Table 2).
In the association analysis of lipids, significant heterogeneity was identified in the total comparisons for TG, TC, LDL-C, and HDL-C (Table 3). Sixteen, nine, ten, and eleven comparisons were respectively recognized as the main contributors to the heterogeneity for TG, TC, LDL-C, HDL-C, by performing Galbraith plots. The analysis results of lipids did not change substantially after excluding the outlier comparisons (Table 4).

Univariate and multivariate meta-regression analysis was also conducted to explore sources of heterogeneity among the included studies. Furthermore, the analyses revealed that the total sample size (Table S4, Table S5) was a significant source of heterogeneity of TG $\left(P_{\text {univariate }}=0.05\right)$ and HDL-C $\left(P_{\text {univariate }}<0.01, P_{\text {multivariate }}=0.01\right)$. Also, the disease status (Table S6) was a significant source of heterogeneity of adiponectin $\left(P_{\text {univariate }}<0.001, P_{\text {multivariate }}<0.001\right)$. However, no confounding factors (Table S7-S9) explain the heterogeneity of leptin ( $P$-values 0.51 to 0.98$), \mathrm{TC}(P$-values 0.37 to 0.85$)$, and LDL-C ( $P$-values 0.10 to 0.82$)$.

\section{Sensitivity analyses}

In association analysis of the Trp64Arg polymorphism with plasma adipokines and lipids levels, a sensitivity analysis was conducted by calculating all results again after omitting every single study. Interestingly, the analysis results of adipokines and plasma lipids did not change substantially after omitting these studies, which indicated that the analysis results were robust and stable.

\section{Publication bias test}

Begg's test and Egger's test were used to evaluating the publication bias of the included studies, and no publication bias 
Table 3 Meta-analysis of the ADRB3 Trp64Arg polymorphism with plasma lipid levels

\begin{tabular}{|c|c|c|c|c|}
\hline Groups or subgroups & Comparisons (Subjects) & $\operatorname{SMD}(95 \% \mathrm{Cl})$ & $P_{\text {Heterogeneity }}$ & $P_{S M D}$ \\
\hline \multicolumn{5}{|l|}{ TG } \\
\hline All & $162(43,778)$ & $0.07(0.03-0.11)$ & $<0.001$ & $<0.001$ \\
\hline Studies in HWE & $142(38,507)$ & $0.05(0.02-0.09)$ & $<0.001$ & 0.01 \\
\hline Caucasian & $47(17,065)$ & $0.09(0.02-0.16)$ & $<0.01$ & $<0.01$ \\
\hline Asian & $101(24,424)$ & $0.06(0.02-0.11)$ & $<0.01$ & $<0.01$ \\
\hline Chilean & $3(340)$ & $0.04(-0.41-0.50)$ & 0.02 & 0.85 \\
\hline Brazilian & $2(223)$ & $0.22(-0.13-0.57)$ & 0.37 & 0.22 \\
\hline Indonesian & $4(531)$ & $-0.18(-0.45-0.09)$ & 0.84 & 0.20 \\
\hline Other ethnic & $5(1195)$ & $0.14(-0.16-0.45)$ & $<0.01$ & 0.35 \\
\hline Female & $40(10,329)$ & $0.06(0.01-0.11)$ & 0.01 & 0.01 \\
\hline Male & 30 (9499) & $0.03(-0.02-0.08)$ & $<0.01$ & 0.30 \\
\hline Obesity & $38(5772)$ & $0.12(0.05-0.18)$ & 0.32 & $<0.01$ \\
\hline T2DM & $20(4335)$ & $0.03(-0.01-0.07)$ & $<0.001$ & 0.07 \\
\hline Hypertension & $4(781)$ & $-0.05(-0.22-0.13)$ & 0.28 & 0.61 \\
\hline$C A D$ & $7(1225)$ & $-0.12(-0.25-0.01)$ & 0.46 & 0.07 \\
\hline Healthy subjects & $69(25,873)$ & $0.05(0.00-0.10)$ & $<0.001$ & 0.03 \\
\hline Children & $14(2337)$ & $0.12(-0.05-0.29)$ & $<0.001$ & 0.16 \\
\hline \multicolumn{5}{|l|}{ TC } \\
\hline All & $162(49,738)$ & $0.04(0.01-0.07)$ & $<0.001$ & 0.01 \\
\hline Studies in HWE & $140(43,716)$ & $0.03(0.01-0.05)$ & $<0.001$ & 0.01 \\
\hline Caucasian & $46(19,238)$ & $0.07(0.00-0.13)$ & $<0.01$ & 0.04 \\
\hline Asian & $104(27,572)$ & $0.02(0.00-0.05)$ & $<0.001$ & 0.05 \\
\hline Chilean & $3(340)$ & $0.04(-0.19-0.27)$ & 0.83 & 0.73 \\
\hline Brazilian & $4(1310)$ & $0.09(-0.06-0.24)$ & 0.52 & 0.23 \\
\hline Other ethnic & $5(1278)$ & $0.00(-0.27-0.27)$ & $<0.01$ & 0.98 \\
\hline Female & $38(11,568)$ & $0.06(0.02-0.11)$ & 0.23 & 0.01 \\
\hline Male & $29(9543)$ & $-0.00(-0.08-0.08)$ & $<0.01$ & 0.92 \\
\hline Obesity & $36(5400)$ & $0.07(0.00-0.13)$ & 0.32 & 0.04 \\
\hline $\mathrm{T} 2 \mathrm{DM}$ & $20(5257)$ & $0.04(-0.02-0.11)$ & 0.75 & 0.22 \\
\hline Hypertension & $6(1182)$ & $0.04(-0.10-0.18)$ & 0.57 & 0.54 \\
\hline CAD & $7(1225)$ & $-0.11(-0.27-0.06)$ & 0.28 & 0.20 \\
\hline Healthy subjects & $68(27,441)$ & $0.05(0.01-0.10)$ & $<0.001$ & 0.02 \\
\hline Children & $14(2279)$ & $0.03(-0.13-0.20)$ & $<0.01$ & 0.67 \\
\hline \multicolumn{5}{|l|}{ LDL-C } \\
\hline All & $103(25,965)$ & $0.03(-0.02-0.07)$ & $<0.001$ & 0.24 \\
\hline Studies in HWE & $86(21,459)$ & $-0.01(-0.05-0.04)$ & 0.01 & 0.82 \\
\hline Caucasian & $29(7687)$ & $0.01(-0.06-0.07)$ & 0.07 & 0.88 \\
\hline Asian & $64(15,264)$ & $0.04(-0.02-0.09)$ & $<0.001$ & 0.22 \\
\hline Brazilian & $4(1310)$ & $0.02(-0.35-0.38)$ & 0.02 & 0.94 \\
\hline Other ethnic & $5(1338)$ & $0.07(-0.17-0.30)$ & 0.01 & 0.59 \\
\hline Female & $24(5800)$ & $0.05(-0.02-0.11)$ & 0.30 & 0.17 \\
\hline Male & $19(3140)$ & $-0.04(-0.17-0.08)$ & 0.01 & 0.51 \\
\hline Obesity & $30(4930)$ & $0.01(-0.06-0.08)$ & 0.36 & 0.81 \\
\hline T2DM & $10(2345)$ & $0.17(-0.06-0.40)$ & $<0.001$ & 0.14 \\
\hline
\end{tabular}


Table 3 Meta-analysis of the ADRB3 Trp64Arg polymorphism with plasma lipid levels (Continued)

\begin{tabular}{|c|c|c|c|c|}
\hline Groups or subgroups & Comparisons (Subjects) & $\operatorname{SMD}(95 \% \mathrm{Cl})$ & $P_{\text {Heterogeneity }}$ & $P_{\mathrm{SMD}}$ \\
\hline CAD & $6(1040)$ & $-0.05(-0.18-0.09)$ & 0.87 & 0.51 \\
\hline Healthy subjects & $39(12,149)$ & $0.05(-0.02-0.12)$ & $<0.001$ & 0.20 \\
\hline Children & $11(2080)$ & $0.10(-0.09-0.30)$ & $<0.001$ & 0.30 \\
\hline \multicolumn{5}{|l|}{$\mathrm{HDL}-\mathrm{C}$} \\
\hline All & $164(49,069)$ & $-0.05(-0.08--0.02)$ & $<0.001$ & $<0.01$ \\
\hline Studies in HWE & $144(43,919)$ & $-0.04(-0.07--0.01)$ & $<0.001$ & 0.03 \\
\hline Caucasian & $45(17,720)$ & $-0.06(-0.08--0.04)$ & 0.60 & 0.05 \\
\hline Asian & $102(27,648)$ & $-0.05(-0.09--0.01)$ & $<0.001$ & 0.02 \\
\hline Chilean & $3(340)$ & $-0.10(-0.33-0.13)$ & 0.37 & 0.38 \\
\hline Brazilian & $4(1310)$ & $-0.14(-0.33-0.04)$ & 0.62 & 0.22 \\
\hline Indonesian & $4(531)$ & $-0.07(-0.34-0.20)$ & 0.52 & 0.59 \\
\hline Other ethnic & $4(613)$ & $-0.32(-0.58--0.07)$ & 0.13 & 0.01 \\
\hline Female & $40(12,250)$ & $-0.04(-0.08--0.00)$ & 0.22 & 0.05 \\
\hline Male & $31(9407)$ & $-0.01(-0.08-0.07)$ & 0.01 & 0.91 \\
\hline Obesity & $36(5310)$ & $-0.06(-0.10--0.02)$ & $<0.01$ & 0.04 \\
\hline T2DM & $19(3575)$ & $-0.17(-0.30--0.04)$ & $<0.01$ & 0.01 \\
\hline Hypertension & $4(957)$ & $0.01(-0.15-0.16)$ & 0.10 & 0.91 \\
\hline CAD & 8 (1532) & $-0.14(-0.37-0.09)$ & 0.01 & 0.23 \\
\hline Healthy subjects & $72(27,600)$ & $-0.00(-0.03-0.03)$ & 0.16 & 0.93 \\
\hline Children & $15(2409)$ & $-0.09(-0.18-0.00)$ & 0.06 & 0.06 \\
\hline
\end{tabular}

ADRB3 beta3-adrenergic receptor gene, SMD standardized mean difference, $95 \%$ Cl 95\% confidence interval, HWE Hardy-Weinberg equilibrium, TG triglycerides, TC total cholesterol, $L D L-C$ low-density lipoprotein cholesterol, $H D L-C$ high-density lipoprotein cholesterol, $C A D$ coronary artery disease, $T 2 D M$ type 2 diabetes mellitus

was detected $(P=0.90$ for leptin, 0.68 for adiponectin, 0.89 for TG, 0.28 for TC, 0.39 for LDL-C, 0.37 for HDL-C, respectively).

\section{Discussion}

The present study showed that the ADRB3 Trp64Arg polymorphism is robustly associated with abnormal levels of adipokines and lipids. This indicates that the ADRB3 Trp64Arg polymorphism may represent a genetic risk factor for CAD.

The specific mechanisms in which the $A D R B 3$ Trp64Arg polymorphism with abnormal adipokines have not been clarified yet. One possible mechanism can be proposed to explain the relationship between the Trp64Arg variant and abnormal adipokines levels: The mutation $\mathrm{C}$ allele of $A D R B 3$ results in low mRNA expression levels [38] and low protein activity [39] of hormone-sensitive lipase (HSL), the reduce lipase concentration and protein activity will no doubt initiate or accelerate obesity [30-32]. Interestingly, this hypothesis is verified in this meta-analysis, since the data shows that the mutation $\mathrm{C}$ allele of $A D R B 3$ is robustly associated with obesity (Table 3 , Table 4), as described above, the obesity is related to abnormal levels of adipokines [16]. This may explain the present findings.

Several possible mechanisms can be proposed to explain the relationship between the ADRB3 Trp64Arg variant and dyslipidemia. At first, HSL can promote the free fatty acid and glycerol release from white adipose tissue $[40,41]$ into the plasma, and the changed lipase concentration and protein activity caused by $\mathrm{C}$ allele [38, 39] will no doubt influence the plasma concentration of free fatty acid and glycerol, thereby induced dyslipidemia. Secondly, Li et al. [42] have conducted an animal study in 40 apolipoprotein $\mathrm{E}(A P O E)$ gene knock-out mice. Their data suggest that the $A D R B 3$ gene may trigger dyslipidemia by regulating the expression of proprotein convertase subtilisin/kexin type 9 (PCSK9) gene and LDL receptor (LDLR) gene. It is widely known that both PCSK9 and LDLR are lipid metabolism-regulated genes, thereby the Trp64Arg polymorphism may indirectly affect plasma lipids levels by regulating lipid metabolismregulated genes expression. Thirdly, whereas both leptin [10-12] and adiponectin [13-15] are related to dyslipidemia, the Trp64Arg variant may indirectly affect lipids levels through the mediation of adipokines. Interestingly, this hypothesis may also verify in this meta-analysis. The data in the present study shows that the mutation $C$ allele of Trp64Arg polymorphism only has a slight effect on plasma levels of lipids (Table 3, Table 4), but a strong effect on plasma levels of adipokines (Table 1, Table 2). Whose SMD values are much larger than those calculated in plasma lipids. As mentioned above, adipokines as a lipid 
Table 4 Meta-analysis of the ADRB3 Trp64Arg polymorphism with plasma lipid levels after excluding the study with heterogeneity

\begin{tabular}{|c|c|c|c|c|}
\hline Groups or subgroups & Comparisons (Subjects) & SMD $(95 \% \mathrm{Cl})$ & $P_{\text {Heterogeneity }}$ & $P_{S M D}$ \\
\hline \multicolumn{5}{|l|}{ TG } \\
\hline All & $146(38,535)$ & $0.04(0.01-0.06)$ & 0.07 & $<0.01$ \\
\hline Studies in HWE & $130(34,679)$ & $0.02(0.00-0.05)$ & 0.24 & 0.05 \\
\hline Caucasian & $42(14,786)$ & $0.04(-0.01-0.09)$ & 0.37 & 0.08 \\
\hline Asian & $92(21,766)$ & $0.04(0.01-0.07)$ & 0.05 & 0.01 \\
\hline Chilean & $2(234)$ & $-0.18(-0.47-0.10)$ & 0.79 & 0.21 \\
\hline Brazilian & $2(223)$ & $0.22(-0.13-0.57)$ & 0.37 & 0.22 \\
\hline Indonesian & $4(531)$ & $-0.18(-0.45-0.09)$ & 0.84 & 0.20 \\
\hline Other ethnic & $4(995)$ & $-0.05(-0.19-0.09)$ & 0.28 & 0.51 \\
\hline Female & $38(10,163)$ & $0.05(0.00-0.10)$ & 0.05 & 0.05 \\
\hline Male & $26(7602)$ & $0.01(-0.05-0.06)$ & 0.30 & 0.83 \\
\hline Obesity & 37 (5290) & $0.09(0.02-0.16)$ & 0.49 & 0.01 \\
\hline T2DM & 17 (3592) & $0.13(0.05-0.21)$ & 0.42 & $<0.01$ \\
\hline Hypertension & $4(781)$ & $-0.05(-0.22-0.13)$ & 0.28 & 0.61 \\
\hline$C A D$ & $7(1225)$ & $-0.12(-0.25-0.01)$ & 0.46 & 0.07 \\
\hline Healthy & $62(22,922)$ & $0.02(-0.02-0.05)$ & 0.08 & 0.35 \\
\hline Children & $11(2025)$ & $0.08(-0.01-0.18)$ & 0.68 & 0.08 \\
\hline \multicolumn{5}{|l|}{ TC } \\
\hline All & $153(46,775)$ & $003(0.01-0.05)$ & 0.11 & $<0.01$ \\
\hline Studies in HWE & $133(41,641)$ & $0.03(0.01-0.06)$ & 0.17 & 0.01 \\
\hline Caucasian & $42(17,507)$ & $0.04(-0.01-0.08)$ & 0.43 & 0.11 \\
\hline Asian & $99(26,340)$ & $0.03(0.01-0.06)$ & 0.20 & 0.01 \\
\hline Chilean & $3(340)$ & $0.04(-0.19-0.27)$ & 0.83 & 0.73 \\
\hline Brazilian & $4(1310)$ & $0.09(-0.06-0.24)$ & 0.52 & 0.23 \\
\hline Other ethnic & $5(1278)$ & $0.00(-0.27-0.27)$ & $<0.01$ & 0.98 \\
\hline Female & $36(11,377)$ & $0.05(0.00-0.10)$ & 0.76 & 0.04 \\
\hline Male & $25(7681)$ & $-0.01(-0.06-0.05)$ & 0.34 & 0.81 \\
\hline Obesity & $35(5269)$ & $0.08(0.00-0.15)$ & 0.70 & 0.04 \\
\hline $\mathrm{T} 2 \mathrm{DM}$ & $20(5257)$ & $0.04(-0.02-0.11)$ & 0.75 & 0.22 \\
\hline Hypertension & $6(1182)$ & $0.04(-0.10-0.18)$ & 0.57 & 0.54 \\
\hline$C A D$ & 7 (1225) & $-0.13(-0.26-0.00)$ & 0.28 & 0.06 \\
\hline Healthy & $62(25,355)$ & $0.03(-0.00-0.06)$ & 0.13 & 0.07 \\
\hline Children & 12 (2039) & $0.04(-0.05-0.14)$ & 0.39 & 0.36 \\
\hline \multicolumn{5}{|l|}{ LDL-C } \\
\hline All & $93(22,397)$ & $0.02(-0.01-0.05)$ & 0.54 & 0.16 \\
\hline Studies in HWE & $81(19,151)$ & $0.02(-0.02-0.05)$ & 0.49 & 0.38 \\
\hline Caucasian & 27 (7116) & $-0.01(-0.08-0.06)$ & 0.49 & 0.84 \\
\hline Asian & $58(12,539)$ & $0.04(0.00-0.08)$ & 0.52 & 0.04 \\
\hline Brazilian & $3(1238)$ & $-0.03(-0.19-0.12)$ & 0.20 & 0.67 \\
\hline Other ethnic & $4(1138)$ & $-0.07(-0.20-0.06)$ & 0.85 & 0.31 \\
\hline Female & $23(5740)$ & $0.04(-0.03-0.10)$ & 0.66 & 0.29 \\
\hline Male & $17(2512)$ & $0.01(-0.08-0.10)$ & 0.12 & 0.84 \\
\hline Obesity & $29(4688)$ & $0.02(-0.05-0.09)$ & 0.57 & 0.55 \\
\hline T2DM & $8(1890)$ & $0.03(-0.08-0.14)$ & 0.44 & 0.62 \\
\hline
\end{tabular}


Table 4 Meta-analysis of the ADRB3 Trp64Arg polymorphism with plasma lipid levels after excluding the study with heterogeneity (Continued)

\begin{tabular}{|c|c|c|c|c|}
\hline Groups or subgroups & Comparisons (Subjects) & SMD $(95 \%$ Cl) & $P_{\text {Heterogeneity }}$ & $P_{\text {SMD }}$ \\
\hline CAD & $6(1040)$ & $-0.05(-0.18-0.09)$ & 0.87 & 0.51 \\
\hline Healthy & 34 (9862) & $0.05(-0.00-0.09)$ & 0.22 & 0.07 \\
\hline Children & $8(1768)$ & $0.10(-0.00-0.20)$ & 0.42 & 0.06 \\
\hline \multicolumn{5}{|l|}{ HDL-C } \\
\hline All & $150(43,951)$ & $-0.04(-0.06--0.02)$ & 0.55 & 0.01 \\
\hline Studies in HWE & $134(39,781)$ & $-0.03(-0.06--0.01)$ & 0.22 & 0.01 \\
\hline Caucasian & $45(17,720)$ & $-0.04(-0.09-0.00)$ & 0.60 & 0.06 \\
\hline Asian & $90(23,675)$ & $-0.03(-0.06--0.01)$ & 0.05 & 0.02 \\
\hline Chilean & $3(340)$ & $-0.10(-0.33-0.13)$ & 0.37 & 0.38 \\
\hline Brazilian & $3(295)$ & $0.21(-0.09-0.50)$ & 0.42 & 0.17 \\
\hline Indonesian & $4(531)$ & $-0.07(-0.34-0.20)$ & 0.52 & 0.59 \\
\hline Other ethnic & $3(483)$ & $-0.23(-042--0.04)$ & 0.55 & 0.02 \\
\hline Female & $38(11,946)$ & $-0.05(-0.10--0.00)$ & 0.73 & 0.03 \\
\hline Male & 27 (8774) & $-0.02(-0.07-0.03)$ & 0.13 & 0.50 \\
\hline Obesity & $33(5017)$ & $-0.05(-0.10--0.00)$ & 0.17 & 0.05 \\
\hline T2DM & $15(1923)$ & $-0.15(-0.25--0.05)$ & 0.68 & $<0.01$ \\
\hline Hypertension & $4(957)$ & $0.01(-0.15-0.16)$ & 0.10 & 0.91 \\
\hline$C A D$ & 7 (1403) & $-0.07(-0.19-0.06)$ & 0.09 & 0.31 \\
\hline Healthy & $67(24,960)$ & $-0.02(-0.05-0.01)$ & 0.49 & 0.21 \\
\hline Children & $14(2279)$ & $-0.07(-0.15-0.02)$ & 0.33 & 0.15 \\
\hline
\end{tabular}

ADRB3 beta3-adrenergic receptor gene, SMD standardized mean difference, 95\% Cl 95\% confidence interval, HWE Hardy-Weinberg equilibrium, TG triglycerides, TC total cholesterol, $L D L-C$ low-density lipoprotein cholesterol, HDL-C high-density lipoprotein cholesterol, CAD coronary artery disease, T2DM type 2 diabetes mellitus

regulator [4-6] play a critical role in lipid metabolism [79]. This may also explain the present findings.

In the present meta-analysis, the significant effects of the Trp64Arg variant on lipid levels were only in Asians (Table 4), it indicates that there is an interaction between the Trp64Arg variant and ethnicity in modulating the plasma lipids. Gender might modulate the association of the Trp64Arg variant with plasma lipids since the significant effects of the Trp64Arg variant on lipid levels were only in Females (Table 4). Disease status might also modulate the association of the Trp64Arg variant with plasma lipids since the significant effects of the Trp64Arg variant on lipid levels were mainly from patients with obesity (Table 3 , Table 4 ). Besides, whose SMD values were much smaller than those calculated in adipokines (Table 1, Table 2). When combined with the previous findings [43], it indicated that the association of the Trp64Arg variant with obesity might partly be mediated by the effect of this variant on adipokines.

\section{Strengths and limitations}

Several strengths of the present meta-analysis should be put forward. Firstly, the present meta-analysis had the sufficiently high statistical power to examine the associations of the Trp64Arg polymorphism with adipokines and plasma lipids in a large sample size, which would increase the reliability of the calculated results. Secondly, the calculated results were obtained after excluding the studies with heterogeneity, which would undoubtedly contribute to drawing some scientific and precise conclusions in the present meta-analysis. Thirdly, the multilevel analyses were performed by ethnicity, disease status, gender, healthy subjects, and children subjects, which would undoubtedly be beneficial to generate some comprehensive and diversified results in this present study. The main limitation of the present meta-analysis was that multiple genetic and environmental factors triggered dyslipidemia. However, the interactions between Trp64Arg polymorphism and other genetic or environmental factors on plasma lipids have not been investigated in this work due to the lack of original data.

\section{Conclusions}

The $\mathrm{C}$ allele carriers of Trp64Arg polymorphism had a slight but significant influence on lipid levels, and the remarkable effects specific existed in obese Asian women. The associations of Trp64Arg polymorphism with dyslipidemia may partly be mediated by the effect of this polymorphism on adipokines. The association of Trp64Arg polymorphism with obesity may partly be 
mediated by the effect of this polymorphism on adipokines. The $\mathrm{C}$ allele carriers had abnormal levels of adipokines and lipids, and it indicated that the Trp64Arg polymorphism might represent a genetic risk factor for CAD.

\section{Supplementary information}

Supplementary information accompanies this paper at https://doi.org/10. 1186/s12944-020-01290-y.

Additional file $\mathbf{1}$ Table S1. Characteristics of the included studies in this systematic review of plasma adipokines and lipids levels for the ADRB3 Trp64Arg polymorphism. Table S2. Plasma adipokines levels by the genotypes of the ADRB3 Trp64Arg polymorphism. Table S3. Plasma lipids levels by the genotypes of the ADRB3 Trp64Arg polymorphism.

Table S4. Meta-regression analysis explores the sources of heterogeneity of plasma triglycerides (TG) levels. Table S5. Meta-regression analysis explores the sources of heterogeneity of plasma high-density lipoprotein cholesterol (HDL-C) levels. Table S6. Meta-regression analysis explores the sources of heterogeneity of plasma adiponectin levels. Table S7. Meta-regression analysis explores the sources of heterogeneity of plasma leptin levels. Table S8. Meta-regression analysis explores the sources of heterogeneity of plasma total cholesterol (TC) levels. Table S9. Metaregression analysis explores the sources of heterogeneity for circulating low-density lipoprotein cholesterol (LDL-C) levels. Supplementary References: The reference list of the included studies in this systematic review.

\section{Abbreviations}

ADRB3: $\beta 3$ adrenergic receptor; CAD: Coronary artery disease; T2DM: Type 2 diabetes mellitus; TG: Triglycerides; TC: Total cholesterol; LDL-C: Low-density lipoprotein cholesterol; HDL-C: High-density lipoprotein cholesterol; HSL: Hormone-sensitive lipase; SMD: Standardized mean difference; 95\% Cl: 95\% confidence interval; SD: Standard deviation; APOE: Apolipoprotein E; PCSK9: Proprotein convertase subtilisin/kexin type 9; LDLR: LDL receptor; CNKI: China National Knowledge Infrastructure; CBM: China Biology Medicine; HWE: Hardy-Weinberg equilibrium

\section{Acknowledgments}

None.

\section{Availability to data and materials}

All extracted data in this study have been used in previously published articles.

\section{Authors' contributions}

Luo $Z$ designed and carried out this study and drafted the manuscript. Luo Z, Cao WZ, Zhang T, Wang SP, He YX, and Ye QT conducted the literature selection process and extracted the data. Luo Z, Cao WZ, and Zhang T performed the statistical analyses. All authors approved the final manuscript.

\section{Funding}

This work was funded by the Sichuan University-Zigong Cooperation ResearchFund (2018CDZG-21) and Sichuan Provincial Medical Association (S15089, S17085).

\section{Ethics approval and consent to participate}

Not applicable.

\section{Consent for publication}

Not applicable.

\section{Competing interests}

The authors declare no conflict of interest.

\section{Author details}

'Department of Cardiology, The First People's Hospital of Zigong, Zigong 643000, People's Republic of China. ${ }^{2}$ Department of Nursing, Sichuan
Vocational College of Health and Rehabilitation, Zigong 643000, People's Republic of China. ${ }^{3}$ North Sichuan Medical College, Nanchong 637000, People's Republic of China. ${ }^{4}$ Office of Research Affairs, The First People's Hospital of Zigong, Zigong 643000, People's Republic of China.

Received: 9 January 2020 Accepted: 15 May 2020

Published online: 19 May 2020

\section{References}

1. Bickel C, Schnabel RB, Zeller T, Lackner KJ, Rupprecht HJ, Blankenberg S, et al. Predictors of leptin concentration and association with cardiovascular risk in patients with coronary artery disease: results from the AtheroGene study. Biomarkers. 2017:22:210-8.

2. Laughlin GA, Barrett-Connor E, May S, Langenberg C. Association of adiponectin with coronary heart disease and mortality: the rancho Bernardo study. Am J Epidemiol. 2007;165:164-74.

3. O'Donnell FL, Stahlman S, Oetting AA. Incidence rates of diagnoses of cardiovascular diseases and associated risk factors, active component, U.S. Armed Forces, 2007-2016. MSMR. 2018;25:12-8.

4. Iqbal J, Mascareno E, Chua S, Hussain MM. Leptin-mediated differential regulation of microsomal triglyceride transfer protein in the intestine and liver affects plasma lipids. J Biol Chem. 2020;295:4101-13.

5. Mora C, Pintado C, Rubio B, Mazuecos L, López V, Fernández A, et al. Central leptin regulates heart lipid content by selectively increasing PPAR $\beta / \delta$ expression. J Endocrinol. 2018;236:43-56.

6. Jung YR, Lee JH, Sohn KC, Lee Y, Seo YJ, Kim CD, et al. Adiponectin signaling regulates lipid production in human Sebocytes. PLoS One. 2017; 12:e169824.

7. Katsiki N, Mantzoros C, Mikhailidis DP. Adiponectin, lipids and atherosclerosis. Curr Opin Lipidol. 2017;28:347-54.

8. Christou GA, Kiortsis DN. Adiponectin and lipoprotein metabolism. Obes Rev. 2013;14:939-49.

9. Dastani Z, Hivert MF, Timpson N, Perry JR, Yuan X, Scott RA, et al. Novel loci for adiponectin levels and their influence on type 2 diabetes and metabolic traits: a multi-ethnic meta-analysis of 45,891 individuals. PLoS Genet. 2012;8: e1002607.

10. Lee S, Kweon OK, Kim WH. Associations between serum leptin levels, hyperlipidemia, and cholelithiasis in dogs. PLoS One. 2017;12:e0187315.

11. Bayramukova AA, Alibaeva NT, Satarov N. The association of leptin with dyslipidemia, arterial hypertension and obesity in Kyrgyz (central Asian nation) population. BMC Res Notes. 2014;7:411.

12. Hahn B, Lourenco E, Likuni N, Cava LA. T.113. Leptin Worsens Hyperlipidemia and Atherosclerosis Induced by High Fat Diet in (NZB $\times$ NZW) F1 Lupus-Prone Mice. Clin Immunol. 2009:131:S84.

13. Marso SP, Mehta SK, Frutkin A, House JA, McCrary JR, Kulkarni KR. Low adiponectin levels are associated with atherogenic dyslipidemia and lipidrich plaque in nondiabetic coronary arteries. Diabetes Care. 2008;31:989-94.

14. Matsubara M, Maruoka S, Katayose S. Decreased plasma adiponectin concentrations in women with dyslipidemia. J Clin Endocrinol Metab. 2002; 8:2764-9.

15. Tomčík M, Arima K, Hulejová H, Kuklová M, Filková M, Braun M, et al. Adiponectin relation to skin changes and dyslipidemia in systemic sclerosis. Cytokine. 2012;58:165-8

16. Fu Y, Luo N, Klein RL, Garvey WT. Adiponectin promotes adipocyte differentiation, insulin sensitivity, and lipid accumulation. J Lipid Res. 2005;4: 1369-79.

17. Kotani K, Sakane N, Saiga K, Kurozawa Y. Leptin: adiponectin ratio as an atherosclerotic index in patients with type 2 diabetes: relationship of the index to carotid intima-media thickness. Diabetologia. 2005:48:2684-6.

18. Ramos-Junior ES, Leite GA, Carmo-Silva CC, Taira TM, Neves KB, Colón DF, et al. Adipokine Chemerin bridges metabolic dyslipidemia and alveolar bone loss in mice. J Bone Miner Res. 2017;32:974-84.

19. Jung UJ, Choi MS. Obesity and its metabolic complications: the role of adipokines and the relationship between obesity, inflammation, insulin resistance, dyslipidemia and nonalcoholic fatty liver disease. Int J Mol Sci. 2014;15:6184-223.

20. Matsuda M, Shimomura I, Sata M, Arita Y, Nishida M, Maeda N, et al. Role of adiponectin in preventing vascular stenosis. The missing link of adipovascular axis. J Biol Chem. 2002;277:37487-91.

21. Satoh N, Naruse M, Usui T, Tagami T, Suganami T, Yamada K, et al. Leptinto-adiponectin ratio as a potential atherogenic index in obese type 2 diabetic patients. Diabetes Care. 2004;27:2488-90. 
22. Myagmar BE, Flynn JM, Cowley PM, Swigart PM, Montgomery MD, Thai $K$, et al. Adrenergic receptors in individual ventricular Myocytes: the Beta-1 and alpha-1B are in all cells, the alpha-1A is in a subpopulation, and the Beta-2 and Beta-3 are mostly absent. Circ Res. 2017;120:110315.

23. Wang Q, Liu Y, Fu Q, Xu B, Zhang Y, Kim S, et al. Inhibiting insulin-mediated $\beta 2$-adrenergic receptor activation prevents diabetes-associated cardiac dysfunction. Circulation. 2017;135:73-88.

24. Himms-Hagen J, Cui J, Danforth E Jr, Taatjes DJ, Lang SS, Waters BL, et al. Effect of CL-316,243, a thermogenic beta 3-agonist, on energy balance and brown and white adipose tissues in rats. Am J Phys. 1994; 266:R1371-82.

25. Carpéné C, Bousquet-Mélou A, Galitzky J, Berlan M, Lafontan M. Lipolytic effects of beta 1-, beta 2-, and beta 3-adrenergic agonists in white adipose tissue of mammals. Ann N Y Acad Sci. 1998:839:186-9.

26. Zhang Y, Matheny M, Zolotukhin S, Tumer N, Scarpace PJ. Regulation of adiponectin and leptin gene expression in white and brown adipose tissues: influence of beta3-adrenergic agonists, retinoic acid, leptin and fasting. Biochim Biophys Acta. 2002;1584:115-22.

27. Komai AM, Musovic S, Peris E, Alrifaiy A, El Hachmane MF, Johansson $M$, et al. White adipocyte Adiponectin exocytosis is stimulated via $\beta 3$ adrenergic signaling and activation of Epac1: catecholamine resistance in obesity and type 2 diabetes. Diabetes. 2016;65:3301-13.

28. Lima RPA, Ribeiro MR, de Farias Lima KQ, Sena EA, de Oliveira CD, Luna RCP, et al. Methylation profile of the ADRB3 gene and its association with lipid profile and nutritional status in adults. Biol Res. 2019;52:21.

29. Jimenez M, Léger B, Canola K, Lehr L, Arboit P, Seydoux J, et al. Beta(1)/beta(2)/beta(3)-adrenoceptor knockout mice are obese and coldsensitive but have normal lipolytic responses to fasting. FEBS Lett. 2002; 530:37-40.

30. Walston J, Silver K, Bogardus C, Knowler WC, Celi FS, Austin S, et al. Time of onset of non-insulin-dependent diabetes mellitus and genetic variation in the beta 3-adrenergic-receptor gene. N Engl J Med. 1995; 333:343-7.

31. Clément K, Vaisse C, Manning BS, Basdevant A, Guy-Grand B, Ruiz J, et al, Genetic variation in the beta 3-adrenergic receptor and an increased capacity to gain weight in patients with morbid obesity. N Engl J Med. 1995;333:352-4.

32. Widén E, Lehto M, Kanninen T, Walston J, Shuldiner AR, Groop LC. Association of a polymorphism in the beta 3-adrenergic-receptor gene with features of the insulin resistance syndrome in Finns. N Engl J Med. 1995;333: 348-51.

33. Daghestani M, Daghestani M, Daghistani M, Eldali A, Hassan ZK, Elamin $\mathrm{MH}$, et al. ADRB3 polymorphism rs4994 (Trp64Arg) associates significantly with bodyweight elevation and dyslipidaemias in Saudis but not rs1801253 (Arg389Gly) polymorphism in ARDB1. Lipids Health Dis. 2018;17:58.

34. Yang M, Huang Q, Wu J, Yin JY, Sun H, Liu HL, et al. Effects of UCP2-866 G/ A and ADRB3 Trp64Arg on rosiglitazone response in Chinese patients with Type 2 diabetes. Br J Clin Pharmacol. 2009;68:14-22.

35. Chen Y, Liao Y, Sun S, Lin F, Li R, Lan S, et al. Stratified meta-analysis by ethnicity revealed that ADRB3 Trp64Arg polymorphism was associated with coronary artery disease in Asians, but not in Caucasians. Medicine (Baltimore). 2020;99:e18914.

36. Begg CB, Mazumdar M. Operating characteristics of a rank correlation test for publication bias. Biometrics. 1994;50:1088-101.

37. DerSimonian R, Kacker R. Random-effects model for meta-analysis of clinical trials: an update. Contemp Clin Trials. 2007;28:105-14.

38. Guillaume JL, Petitjean F, Haasemann M, Bianchi C, Eshdat Y, Strosberg AD. Antibodies for the immunochemistry of the human beta 3-adrenergic receptor. Eur J Biochem. 1994;224:761-70.

39. Umekawa T, Yoshida T, Sakane N, Kogure A, Kondo M, Honjyo H. Trp64Arg mutation of beta3-adrenoceptor gene deteriorates lipolysis induced by beta3-adrenoceptor agonist in human omental adipocytes. Diabetes. 1999; 48:117-20.

40. Berraondo B, Martínez JA. Free fatty acids are involved in the inverse relationship between hormone-sensitive lipase (HSL) activity and expression in adipose tissue after high-fat feeding or beta3-adrenergic stimulation. Obes Res. 2000;8:255-61.
41. Shin JH, Lee SH, Kim YN, Kim IY, Kim YJ, Kyeong DS, et al. AHNAK deficiency promotes browning and lipolysis in mice via increased responsiveness to $\beta$ adrenergic signalling. Sci Rep. 2016;6:23426.

42. Li YF, Jiang ZL, Guo YQ, Song JY. Effect of $\beta 3$-AR agonists on expression of PCSK9 and LDLR in apoE gene knock-out mice. Chin J Geriatr Heart Brain Ves Dis. 2014;16:627-9.

43. Kelly AS, Metzig AM, Schwarzenberg SJ, Norris AL, Fox CK, Steinberger J. Hyperleptinemia and hypoadiponectinemia in extreme pediatric obesity. Metab Syndr Relat Disord. 2012;10:123-7.

\section{Publisher's Note}

Springer Nature remains neutral with regard to jurisdictional claims in published maps and institutional affiliations.
Ready to submit your research? Choose BMC and benefit from:

- fast, convenient online submission

- thorough peer review by experienced researchers in your field

- rapid publication on acceptance

- support for research data, including large and complex data types

- gold Open Access which fosters wider collaboration and increased citations

- maximum visibility for your research: over $100 \mathrm{M}$ website views per year

At BMC, research is always in progress.

Learn more biomedcentral.com/submissions 